\title{
Toxicity of ethylene oxide on the lens and on leukocytes: an epidemiological study in hospital sterilisation installations
}

\author{
D Deschamps, M Leport, A-M Laurent, S Cordier, B Festy, F Conso
}

\begin{abstract}
An epidemiological study was conducted in 55 subjects (mean age: 41 ) in hospitals to determine the prevalence of lens opacities and cataracts in workers exposed to ethylene oxide in six sterilisation units. The 21 exposed subjects over 45 were then compared with 16 non-exposed subjects, matched for age and sex. The relation between occupational exposure to ethylene oxide and white blood cell concentrations was also investigated. Lens opacities (independently of visual acuity) were observed in 19 of the 55 exposed. Among both exposed and non-exposed aged over 45 , there were no significant differences with regard to the characteristics of lens opacities-prevalence (19 in the 21 exposed; 10 in the 16 non-exposed), distribution of the location, and importance and type (opalescence or discontinuous opacities). No link was found between the characteristics of the lens opacities and the characteristics of exposure: habitual exposure, measured between 0.06 and 39 ppm (cumulated in ppm-number of weekly hours-years) and accidental over-exposures (regular and irregular). For cataracts, defined by the association of lens opacities and a visual acuity less than 20/25 (this loss not being attributable to another cause), their prevalence differed significantly $(p<0.05)$ between the exposed (six of 21) and the non-exposed ( 0 of 16); there was no relation between their existence and overexposures (the analysis for habitual exposure was not possible because of the small
\end{abstract}

Service de pathologie professionnelle, Hôpital Cochin, 75014 Paris, France

D Deschamps, F Conso

Service d'ophtalmologie, Hôtel-Dieu, 75004 Paris M Leport

Laboratoire d'Hygiène de la Ville de Paris, 75004 Paris

A M Laurent, B Festy

Unité de recherches épidémiologiques et statistiques sur l'environnement et la santé (INSERM U 170), 94807 Villejuif cedex

S Cordier size of the sample). The risk of lens opacifica- $\frac{\mathbb{D}}{3}$ tions by ethylene oxide in cases of massive exposures as previously described could also ir exist during chronic exposure to low concen- $\omega$ trations. It could be explained by saturation of $\infty$ protective mechanisms against alkylating action of this product. Linear relations were found between the logarithm of the cumulative $\bar{z}$ exposure index and the logarithms of blood concentrations of polymorphoneutrophils $(R \vec{\theta}$ $=-0.54 ; \mathbf{p}<0.005)$ and of lymphocytes $(R=\emptyset$ $-0.45 ; p<0.05)$.

Ethylene oxide is widely used as a precursor for industrial chemicals and to a much lesser extent, as a disinfecting and sterilising product, especially for $\stackrel{2}{\mathbb{D}}$ heat sensitive medical equipment. In recent years the toxicological occupational hazards of ethylene oxide, particularly peripheral neuropathies and leukaemia, have been investigated. ${ }^{1-3}$

Lens toxicity is another area currently studied. In animals McDonald observed lens opacities in rabbits $\mathbb{\perp}$ six hours after conjunctival application of highly concentrated ethylene oxide solution (over $200000 \frac{5}{3}$ ppm); nevertheless, neither location nor importance of the opacities were noted and we do not know 0 whether cataracts resulted from ocular inflammatory disease occasioned by lesser concentrations. ${ }^{4}$

In man Jay reported three cases of posterior and $D$ anterior subcapsular bilateral cataracts in young men aged 30 to 35 who had been exposed for two months $N$ to leaks from a steriliser. ${ }^{5}$ The intermittent smelling of ethylene oxide indicated that the level had been 0 high, greater than $700 \mathrm{ppm} .{ }^{6}$ Nine other operators $\omega$ were examined and had no lens opacities; one hadO worked on the leaking steriliser for only three weekso but up to 70 hours a week; the others had not been $\mathbb{尺}$ exposed to the leak.

In 1985 an occupational health physician drew our attention to three cases and a few months later to two $\frac{\mathrm{d}}{\mathbb{D}}$ others of anterior and posterior subcapsular cataracts $\cong$ in women aged about 30 who were working for one to $\stackrel{\square}{\varrho}$ four hours a day sterilising medical supplies by ethylene oxide. In 1979 they had shown clinical symptoms of ethylene oxide poisoning for fouro weeks: weariness, discomfort, leg weakness, nausea, 
vomiting, and headaches. No other cause of cataract, more particularly endocrinous, were brought to light $^{7}$ (and $\mathbf{P}$ Charles, personal communication, 1988).

The lack of good experimental investigation and of an epidemiological controlled study on the effects of ethylene oxide on lens prompted us to undertake a study of 55 workers in Parisian hospitals. These subjects were recruited from a different population than that of the five cases observed in 1985. A white blood cells count accompanied the clinical investigation.

\section{Subjects, materials, and methods}

The sterilising by ethylene oxide in the units of five hospitals and of the central hospital pharmacy were investigated. The characteristics of the sterilisers areas were analysed with a standardised plan by the occupational health physicians.

Instantaneous atmospheric concentration of ethylene oxide was measured with Draëger tubes; continuous static and individual samples were performed when opening the sterilisers and in the desorption areas in accordance with the technique of the French norm (Association Française de Normalisation), ${ }^{8}$ similar to that which will be recommended by the National Institute of Occupational Safety and Health (NIOSH). ${ }^{9}$ In the fifth hospital it was not possible to perform continuous measurements because sterilisation installations were changed just before this part of the study began.

Fifty five exposed workers (seven to 17 per unit) were examined. Initial results showed that lens opacities were more frequent in those aged over 45 (13 of 21) than in those under 45 (six of 34). Therefore, we compared those exposed with a group of non-exposed hospital staff, matched for age and sex, but only for those aged over 45 .

Each person was examined by his occupational health physician and by an ophthalmologist. The examination conducted by the occupational health physician had two objectives.

(1) Research of the following causes of cataracts: drug induced (with a standardised questionnaire ${ }^{10}$ ) or classically occupational (ionising radiations, heat (...).

(2) Characterisation of the ethylene oxide exposure: type and duration of activity; quantification of habitual exposure, differentiating, if necessary, the various workplaces; and description of overexposures, regular or not.

A white blood cells count was performed in each person.

The lens opacities were determined by slit light examination after pupillary dilatation. We studied lens opacities more extensively than cataracts because the definition of cataract is vague: the association of lens opacities and of loss of visual acuity is accepted worldwide, but there is no consensus on the importance of the deficit, the systematic relation between loss of visual acuity and lens opacities, and the methods of lens examination. We therefore studied lens opacities independently of visual acuity. Epidemiological studies on cataracts use variable and arbitrary criteria of maximal visual acuity. This study used the largest number so far published and adopted by the National Health and Examination Survey ${ }^{11}$ : thus association of lens opacities and visual acuity less than or equal to $20 / 25$ were considered as cataract. This loss could not be attributed to any other pathology.

Opacities were classified according to their location (nuclear, cortical, or posterior subcapsular) and to their importance.

(1) No opacities.

(2) Peripheral opacities only.

(3) Peripheral and central opacities without change in visual acuity.

(4) Peripheral and central opacities with loss of visual acuity but without impairment of fundus visualisation.

(5) Peripheral and central opacities that impaired fundus visualisation.

(6) Peripheral and central opacities that prevented fundus visualisation.

An index of importance of the bilateral cortical opacities was evaluated by determining the average of the figures; three groups were then established: no opacity, few opacities, and higher degree of opacities.

Among the cortical opacities, opalescences were distinguished from the white discontinuous opacities.

The ophthalmological examination also included a standardised questionnaire on the causes of cataracts $^{12}$ : congenital cataracts, trauma or other physical agents, endocrine diseases (a fasting blood sugar has been determined), and ocular disease. Studies of refraction, of visual acuity at close and long range, and examination of the cornea (thickened or not), on the depth of the anterior chamber, ocular pressure, and pupilary aspect to the ophthalmoscopic examination were performed. A Farnsworth 15 Hue test was performed to detect anomalies in colour vision that might indicate toxic optical nevritis (dyschromatopsy of the tritan type).

Habitual exposure was evaluated in two ways. The index of cumulative exposure was calculated by multiplying the number of years in this occupation by the number of weekly hours of exposure by the number of ppm measured. If there were several types of exposure the total value was the sum of the index of cumulative partial exposures-for example, an index for the opening of the steriliser and another for the handling of the supplies. This index has not been evaluated for the workers for whom variation in exposure has been suspected during occupational 
Table 1 Characteristics of cataracts

\begin{tabular}{|c|c|c|c|c|c|c|c|}
\hline \multirow[b]{2}{*}{ Age } & \multirow[b]{2}{*}{ Sex } & \multicolumn{2}{|c|}{ Location of opacities } & \multicolumn{2}{|c|}{ Type of cortical opacities } & \multicolumn{2}{|c|}{ Visual acuity } \\
\hline & & Right eye & Left eye & Right eye & Left eye & Right eye & Left ex \\
\hline $\begin{array}{l}51 \\
48 \\
44 \\
50\end{array}$ & $\begin{array}{l}\mathbf{M} \\
\mathbf{M} \\
\mathbf{M} \\
\mathbf{M}\end{array}$ & $\begin{array}{l}\text { Cortical } \\
\text { Cortical } \\
\text { Cortical } \\
\text { Posterior } \\
\text { subcapsular }\end{array}$ & $\begin{array}{l}\text { Cortical } \\
\text { Cortical } \\
\text { Cortical } \\
\text { Posterior } \\
\text { subcapsular }\end{array}$ & $\begin{array}{l}\text { White } \\
\text { White } \\
\text { White } \\
\text { - }\end{array}$ & $\begin{array}{l}\text { White } \\
\text { White } \\
\text { White } \\
\text { - }\end{array}$ & $\begin{array}{l}20 / 33 \\
20 / 20 \\
20 / 20 \\
20 / 20\end{array}$ & 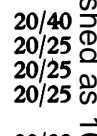 \\
\hline $\begin{array}{l}50 \\
53\end{array}$ & $\mathbf{F}$ & $\begin{array}{l}\text { Cortical } \\
\text { Cortical nuclear }\end{array}$ & $\begin{array}{l}\text { Cortical } \\
\text { Cortical nuclear }\end{array}$ & $\begin{array}{l}\text { White } \\
\text { White }\end{array}$ & $\begin{array}{l}\text { White } \\
\text { White }\end{array}$ & $\begin{array}{l}20 / 25 \\
20 / 22\end{array}$ & $\begin{array}{l}20 / 33 \subseteq \\
20 / 25=\end{array}$ \\
\hline
\end{tabular}

activities; in particular, this has been the case for those who had previously worked in other installations of sterilisation by ethylene oxide; finally, it was calculated for only 26 . This index determined four scores-less than 10,10 to 20,20 to 50 , and over 50 ppm weekly hours-years.

The highest value of partial exposure has also been determined by arbitrarily separating them into two classes: over or less than $5 \mathrm{ppm}$.

The data were analysed using a VAX/VMS computer, using BMDP programs $1 \mathrm{D}, 6 \mathrm{D}, 7 \mathrm{D}$, and $4 \mathrm{~F}$. Prevalence data were compared using the Pearson $\chi^{2}$ test or Fischer's exact test, according to the minimal expected value. The comparisons of averages were performed by analysis of variance.

\section{Results}

\section{INSTALLATIONS}

Atmospheric concentrations, measured by static and individual samples, ranged from $0.06 \mathrm{ppm}$ during a 97 minute exposure (when handling sterilised supplies) to $39 \mathrm{ppm}$ during a 2.5 minute exposure (when the steriliser was opened in another unit). Only two results exceeded the French limit values $(5 \mathrm{ppm}$ for eight hours, $10 \mathrm{ppm}$ for 15 minutes or less).

Over-exposures were noted in 27 subjects (regular for 15 and irregular for 22).

\section{OPHTHALMOLOGICAL EXAMINATION}

Lens opacities were observed in 19 of 55 exposed

Table 2 Location of lens opacities and of cataracts in subjects aged over 45

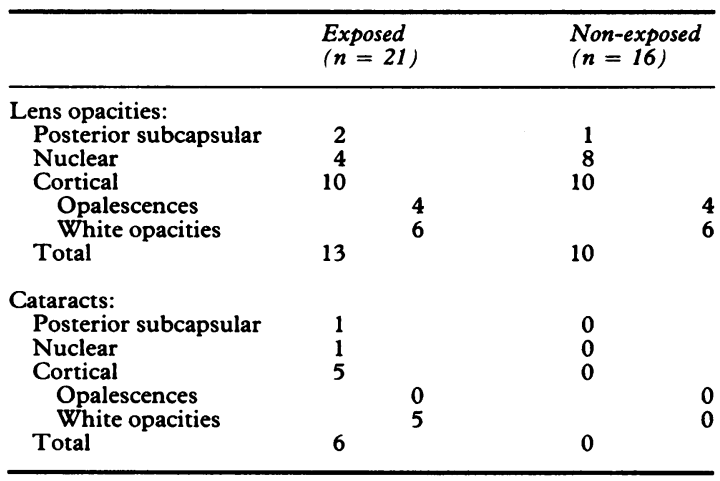

subjects (13 of 21 over 45) and in 10 of 16 nog exposed workers over 45 . For six subjects (of whom only one was under 45) who were all exposed to ethylene oxide, visual acuity was less than or equalito 20/25: this loss could be attributed to the leigs opacification and was evidence of a cataract; the characteristics of these workers are summarised on table 1.

Table 2 shows the details of the locations. The cortical type was more frequent than the subcapsutar type among (1) those over 45 with opacities: in the $\frac{d}{b}$ exposed (cortical 10 subscapsular 2 ) as in the 10 nos exposed (cortical 10, subcapsular 1) and (2) the exposed subjects, in those over 45 as in those under 45. We thus detailed the study of these cortieal opacities.

The prevalence risk factors for cataracts did not differ among the exposed (17 among 21) and the nollexposed (10 among 16) or among the exposed wigh cataract (five among six) and those without cataract (13 among 15).

Among the non-exposed, the average age of the subjects with lens opacities ( 47.9 years) was mufogh higher $(p<0.0001)$ than that of those without such opacities ( 37.8 years). In contrast, cumulatife exposure index was not linked to age, which was therefore not considered as a confounding factor.

The averages of the cumulative exposure indexes differed $(p<0.001)$ when peak concentrations exceeded $5 \mathrm{ppm}(11.56 \mathrm{ppm} /$ weekly hours/years) and were less than $5 \mathrm{ppm}(7.67 \mathrm{ppm} /$ weekly hours/yearg. Therefore, because there was a link between cumstlative exposures and maximal peaks of concentration, we ignored the amounts of peaks of concentration the follow up of the analysis.

The comparison of the characteristics of less opacities between exposed and non-exposed subjeats aged over 45 , and the analysis of these characterist 65 according to the characteristics of exposure yielded the following results.

There was no difference between exposed a idd non-exposed subjects with regard to the following characteristics of lens opacities-prevalence $\overrightarrow{8} f$ lens opacities, distribution of location: cortigal versus non-cortical (nuclear and subcapsularf, importance of the bilateral cortical opacities. No link has been shown between characteristics 


\begin{tabular}{|c|c|c|c|c|}
\hline Other risk factors & $\begin{array}{l}\text { Exposure to } \\
\text { ethylene oxide }\end{array}$ & Type of work & Exposure (y) & Overexposures \\
\hline $\begin{array}{l}\text { Contusion } \\
\text { Ocular burn, contusion } \\
\text { Contusion, atopia } \\
\text { None }\end{array}$ & $\begin{array}{l}\text { Yes } \\
\text { Yes } \\
\text { Yes } \\
\text { Yes }\end{array}$ & $\begin{array}{l}\text { Handling of sterilised supplies } \\
\text { Maintenance of the steriliser } \\
\text { Handling of sterilised supplies } \\
\text { Handling of sterilised supplies }\end{array}$ & $\begin{array}{r}16 \\
12 \\
10 \\
5\end{array}$ & $\begin{array}{l}\text { Regular } \\
\text { Regular, irregular } \\
\text { None } \\
\text { None }\end{array}$ \\
\hline $\begin{array}{l}\text { Ocular burn } \\
\text { None }\end{array}$ & $\begin{array}{l}\text { Yes } \\
\text { Yes }\end{array}$ & $\begin{array}{l}\text { Handling of sterilised supplies } \\
\text { Handling of sterilised supplies }\end{array}$ & $\begin{array}{l}4 \\
3\end{array}$ & $\begin{array}{l}\text { None } \\
\text { None }\end{array}$ \\
\hline
\end{tabular}

the lens opacities and exposure characteristicshabitual exposure (estimated by the cumulative exposure index) and accidental over-exposures (regular or irregular).

By contrast, cataracts (defined by the association of lens opacities with visual acuity less than or equal to $20 / 25$, this loss not being imputable to any other cause) were significantly more frequent $(p<0.05)$ in the exposed (six among 21) than in the non-exposed (none among 16). The sample size was too small to identify a link between the prevalence of cataracts and the importance of habitual exposure (estimated by the cumulative exposure index).

No anomalies were noted during examination of cornea, anterior chambers, ocular tonus, and papilla. Anomalies in colour vision were not significantly more frequent in the exposed than in the nonexposed and were not linked to the existence of overexposures.

\section{BLOOD LEUKOCYTES}

The statistical distribution of each variable was studied and the data were transformed to approach the normal distribution: the distribution of the white blood cells, of polymorphoneutrophils, of lymphocytes (in absolute numbers), and of the cumulative exposure indexes were found to be log normal.

The concentration of white blood cells varied from 3000 to 11500 per $\mathrm{mm}^{3}$, of polymorphoneutrophils from 1620 to 9000 per $\mathrm{mm}^{3}$, and of lymphocytes from 1250 to 4650 per $\mathrm{mm}^{3}$. A linear relation (figure) existed between the logarithm of the cumulative exposure index and the logarithm of: the concentration of white blood cells $(R=-0.55 ; p<0.005)$; the blood concentration of polymorphoneutrophils $(\mathbf{R}=$ $-0.54 ; p<0.005)$; and the blood concentration of lymphocytes $(R=-0.45 ; p<0.05)$.

The averages of concentrations of white blood cells, polymorphoneutrophils, and lymphocytes did not differ between subjects submitted to regular over-exposures and those who were not.

\section{Discussion}

EFFECTS OF ETHYLENE OXIDE ON THE LENS

Cataracts

Cataracts were more common in exposed subjects than in those not exposed to ethylene oxide $(p<$
$0.05)$. They were not linked to the existence of overexposures.

The prevalence of risk factors for cataracts did not differ between exposed and non-exposed subjects and thus does not explain the difference in prevalence of cataracts.

The lens examination was not performed without knowledge of the exposure status. Its subjectivity, however, was limited by the precision of the protocol,
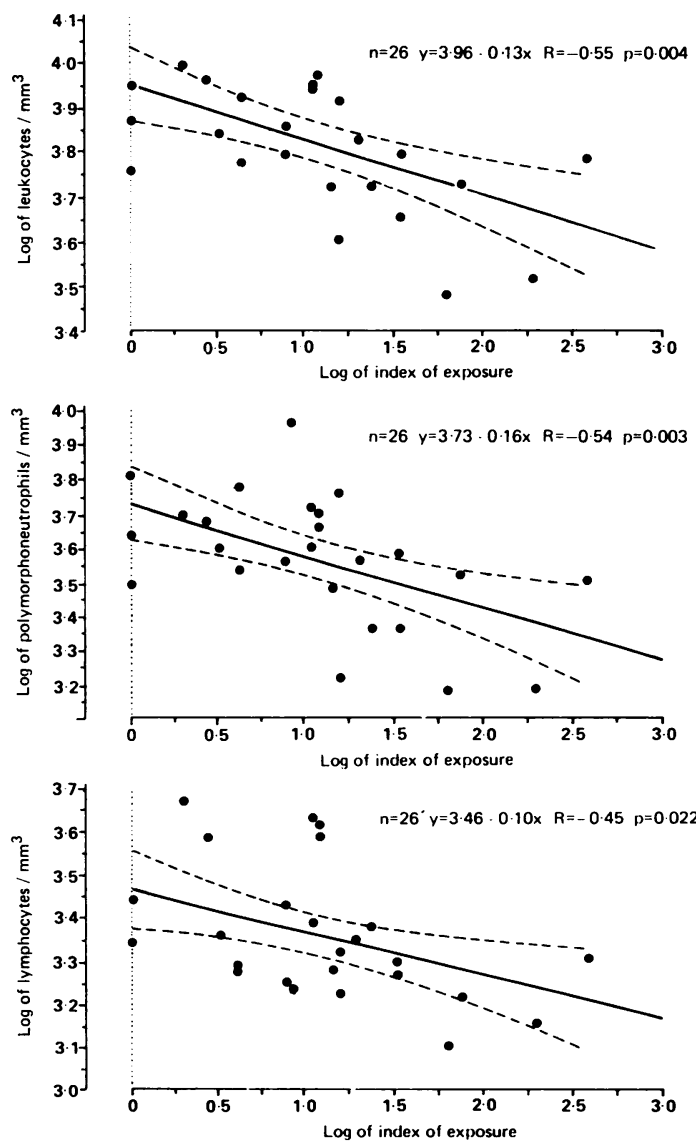

Cumulative exposure and leukocytes (90\% confidence bands for the true mean of $y$ ). 
necessary for a semiquantitative description of the opacities. Moreover, it is visual acuity that is responsible for this difference, since we adopted the following definition of cataract $^{11}$ : association of lens opacities and of visual acuity less than or equal to $20 / 25$, this loss not being imputable to another disease. The measure of visual acuity is objective and was performed by a different, blinded observer.

\section{Lens opacities}

Characteristics of the lens opacities (evaluated independently of the visual acuity): prevalence, location, and importance, did not differ between those exposed and those not exposed to ethylene oxide. They were not linked to the existence of overexposures nor to the habitual exposure evaluated by the cumulative exposure index. It was not possible to distinguish the effects of cumulative exposure and of maximum peak exposure as these two parameters were not independent of each other.

This negative result could be due to a lack of power in the study. Because of the small size of the samples, the power of the test of difference for the prevalence of lens opacities between exposed and non-exposed subjects is low but the same samples showed differences in cataracts and this does not substantiate the hypothesis of a lack of power.

\section{Could ethylene oxide be responsible for the cataracts observed?}

There are several arguments against the responsibility of ethylene oxide in the origin of the cataracts observed in exposed subjects.

The unilateral nature of the disease, whereas toxic and metabolic cataracts are classically bilateral; only two of the six subjects having a cataract had a visual acuity less than or equal to $20 / 25$ bilaterally. The eight cataracts attributed at present to ethylene oxide were subcapsular ${ }^{578}$; in our sample this location was observed in only one person among the six having cataract.

If, by contrast, ethylene oxide is responsible for producing the cataracts noted in the exposed workers several situations may be considered.

(1) An important exposure (probably over $100 \mathrm{ppm}$ for a relatively long but undocumented duration) would induce subcapsular cataracts as previously described. ${ }^{58}$

(2) A continuous, moderate exposure according to the French limit values $(5 \mathrm{ppm}$ for eight hours, 10 ppm for 15 minutes or less) would favour the development of lens opacities followed by cataract. We would then have expected to observe not only more cataracts but also more opacities without impairment of visual acuity in those exposed to those non-exposed, this was not so in our study. Indeed, we could have underestimated the frequency of early opalescences: their clinical detection is more difficult than that of discontinuous opacities. This explanation, however, does not seem valid since no opale cence was detected in subjects who had a catarest and, in contrast, eight cases of opalescence were observed in subjects who had no visual acuiñy impairment (table 2).

(3) A continuous, moderate exposure would favouffa lens opacification and a rapid passage from the stage of opacities without impairment of visual acuity $\vec{\Phi}$ the stage of cataracts. Indeed, we can imagine that ethylene oxide accelerates aging of lenses or the effet of a pathological process. Nevertheless, this phenomenon was not observed in our study; the existenge of other risk factors for cataracts was not moke frequent among the exposed subjects having catarast than among the exposed with normal lenses.

A pathophysiological hypothesis could explam both the existence of the risk of cataract duriRg continuous exposure to weak concentrations in subjects having another risk factor for cataract and during massive exposures of at least several weets. This hypothesis is the depletion of glutathion in the lens when thresholds of concentration and of durese tion are exceeded. Ethylene oxide would then exercise its alkylating action, which probably results on lens opacification.

\section{EFFECTS OF ETHYLENE OXIDE ON CIRCULATING} LEUKOCYTES

Log log linear relation appeared between $t \overrightarrow{6} e$ cumulative exposure index and the blood concentrătions of leukocytes $(R=-0.55 ; p<0.005)$, 㞭 polymorphoneutrophils $(\mathrm{R}=-0.54 ; \mathrm{p}<0.005$, and of lymphocytes $(R=-0.45 ; p<0.05)$. T $\mathrm{ge}$ lowest concentrations did not differ much from the normal range: two subjects presented a concentration of lymphocytes below 1500 per $\mathrm{mm}^{3}$ (1240 and $14 \mathrm{H}$ ) and three a concentration of polymorphoneutrophâs below 1700 per $\mathrm{mm}^{3}$ (1512 for two, 1660 for the third).

There has been little interest in non-carcinogenic haematological effects since Ehrenberg's epidem logical study which reported a result different from ours. ${ }^{13}$

From our finding of diminished leukocytes wh increased exposure to ethylene oxide, we are unable to comment on the risk of leukaemia imputed ethylene oxide.

We thank the occupational health physicians who participated to this study: L Barouhiel, C Delmas, $M$ Giorgi, P Giraud, C Gozlan, M F Maillard, J Marande, A Pelletier, $M$ Véron, E Vibert-Guigue

This study was supported by a grant from to French Department of Employment.

Requests for reprints to: F Conso, service fe Pathologie professionnelle, Hôpital Cochin, 27 rge du faubourg Saint-Jacques, 75014 Paris, France. 
1 World Health Organisation. Ethylene oxide. Environmental health criteria. Geneva: WHO, 1985:55.

2 Hogstedt C, Malmqvist N, Wadman B. Leukemia in workers exposed to ethylene oxide. JAMA 1979;241:1132-3.

3 Hogstedt C, Aringer L, Gustavsson A. Epidemiologic support for ethylene oxide as a cancer causing agent. $J A M A$ 1986; 255:1575-8.

4 McDonald TO, Kasten K, Hevey R, Gregg S, Borgmann AR, Murchison T. Acute ocular toxicity of ethylene oxide, ethylene glycol and ethylene chlorohydrin. Bulletin of the Parenteral Drug Association 1973;27:153-64.

5 Jay WM, Swift TR, Hull DS. Possible relationship of ethylene oxide exposure to cataract formation. Am J Ophthalmol 1982; 93:727-32.

6 Jacobson $\mathrm{KH}$, Hackley EB, Feinsilver L. The toxicity of ethylene oxide and propylene oxide vapors. Archives of Industrial Health 1956;13:237-43.

7 Conso F. Cataracte après exposition à l'oxyde d'éthylène. Le Concours médical 1986;108:315-6.

8 Lefevre C, Ferrari P, Delcour J, Guenier JP, Müller J. Ethylene oxide pollution evaluation. Part II Sampling on Hbr treated charcoal tubes. Chromatographia 1986;21:269-73.

9 Cummins KJ, Schultz GR, Lee JS, Nelson JH, Reading JC. The development and evaluation of a hydrobromic acid-coated sampling tube for measuring occupational exposures to ethylene oxide. Am Ind Hyg Assoc J 1987;48:563-73.

10 Raspillier A, Chevaleraud J, George JL, et al. Les cataractes. In: Effets indésirables des médicaments en ophtalmologie. Bull Soc Ophtalmol Fr rapport annuel, numéro spécial, 1985: 87-107.

11 Leske MC, Sperduto RD. The epidemiology of senile cataracts: a review. Am J Epidemiol 1983;118:152-65.

12 Pouliquen Y. Cristallin. In: Précis d'ophtalmologie. Paris: Masson, 1985:235-60.

13 Ehrenberg L, Hallström T. Haematologic studies on persons occupationally exposed to ethylene oxide. Radiosterilisation of medical product. Vienna: International Atomic Energy Agency, 1967:327-34. (Report No SM 92/26.)

Accepted 17 July 1989

\section{Vancouver style}

All manuscripts submitted to the $\mathrm{Br} J$ Ind $\mathrm{Med}$ should conform to the uniform requirements for manuscripts submitted to biomedical journals (known as the Vancouver style)

The $\mathrm{Br} J$ Ind Med, together with many other international biomedical journals, has agreed to accept articles prepared in accordance with the Vancouver style. The style (described in full in Br Med J, 24 February 1979, p 532) is intended to standardise requirements for authors.

References should be numbered consecutively in the order in which they are first mentioned in the text by Arabic numerals above the line on each occasion the reference is cited (Manson ${ }^{1}$ confirmed other reports ${ }^{2-5} \ldots$ ). In future references to papers submitted to the $\mathrm{Br} J$ Ind Med should include: the names of all authors if there are six or less or, if there are more, the first three followed by et al; the title of journal articles or book chapters; the titles of journals abbreviated according to the style of Index Medicus; and the first and final page numbers of the article or chapter.

Examples of common forms of references are:

1 International Steering Committee of Medical Editors. Uniform requirements for manuscripts submitted to biomedical journals. Br Med J 1979;1:532-5.

2 Soter NA, Wasserman SI, Austen KF. Cold urticaria: release into the circulation of histamine and eosino-phil chemotactic factor of anaphylaxis during cold challenge. $N$ Engl J Med 1976;294:687-90.

3 Weinstein L, Swartz MN. Pathogenic properties of invading micro-organisms. In: Sodeman WA Jr, Sodeman WA, eds. Pathologic physiology: mechanisms of disease. Philadelphia: W B Saunders, 1974:457-72. 